\title{
Supply and demand law under variable information
}

\author{
Guanghui Yuan $^{\mathrm{a}, \mathrm{b}}$, Jingti Han ${ }^{\mathrm{b}, *}$, Lei Zhou ${ }^{\mathrm{c}}$, Hejun Liang ${ }^{\mathrm{b}, \mathrm{d}}$, Yicheng Zhang ${ }^{\mathrm{e}}$ \\ a School of Information Management and Engineering, Shanghai University of Finance and Economics, Shanghai, China \\ ${ }^{\mathrm{b}}$ Fintech Research Institute, Shanghai University of Finance and Economics, Shanghai, China \\ ${ }^{c}$ Faculty of Computer and Software Engineering, Huaiyin Institute of Technology, Huaian, China \\ ${ }^{\mathrm{d}}$ Department of Computer Science, University of Reading, Reading RG6 6AH, United Kingdom \\ e Department of Physics, University of Fribourg, $\mathrm{CH}-1700$ Fribourg, Switzerland
}

\section{H I G H L I G H T S}

- Analyze and study the relationship between supply and demand in the case of variable information capabilities.

- Propose a method to study the relationship between changes in market demand and external resource inputs.

- Calculate the optimal investment timing of different quality products by external resources research through numerical calculation.

- Under the variable information, a set of enterprise income maximization analysis mechanism is formed.

Keywords:

Supply-demand law Information capability Information variable Market choice

\begin{abstract}
When the product quality is limited and the information capability is variable, we propose the enterprise enhances corporate profits by changing the relationship between market demand and external resources. We assume that the information capacity can be changed through the input of external resources. In this paper, we present a research agenda that empowers external resources to transform consumer information capabilities and hence market demand. The result shows that the higher the quality of the product, the more market demand can be obtained by investing in external resources in the early stage. The research of this paper provides a set of models for enterprises to choose a better opportunity to promote their products according to the quality of their products or services, which will help enterprises achieve better returns in the short term.
\end{abstract}

\section{Introduction}

Market participants perceived differences in demand for goods by the market on the impact of product quality awareness [1]. A class of products often have an incomplete understanding of the consumers before they enter the boom period, which would affect the sales. Businesses can further their market needs by enabling them to access more information (improving user perceptions), thereby their business profit goals will be achieved or higher access to enterprises will be gained by vague market perceptions when the market has enough information [2,3].

Clifford Geertz [4], the American anthropologist, has a description of how a market economy works, in which buyers and sellers use intrigue to manipulate product information. The information in the market is asymmetric, that is, sellers

\footnotetext{
* Corresponding author.

E-mail addresses: flame_yuan@163.sufe.edu.cn, guanghuiyuan@outlook.com (G.-H. Yuan), hanjt@mail.shufe.edu.cn (J.-T. Han), lianghejun@fudan.edu.cn (H.-J. Liang), yi-cheng.zhang@unifr.ch (Y.-C. Zhang).
} 
know more about products than buyers. Akerlof G [5], the Berkeley economist, used a simple example to explain the issue of information asymmetry in his Nobel Prize article: "The Lemon Market". He assumes that the information asymmetry increases barriers in many transactions, but only in some extreme cases the markets would failed [5]. Most business transactions are not simply called "success" or "failure". We will show that the weak side with limited information capability in information asymmetry is the key to improve efficiency [6].

It can be found that the seller is always on the side of the information flow, or can change the information in these statements. Therefore, it can be seen that enterprises can change the market information capability. In other words, the consumers increase the possibility of purchasing this service.

The change of information capability can be manipulated intentionally or it can be an inevitable trend of development $[7,8]$. As the consumers' information capabilities improve, the company's profit margins per unit product tend to decline, and the total revenue may increase or decrease. This depends on which part of the information capability is between the two regions. In the different information areas, the attitude of the business is opposite. In one information area, they support strengthening consumers' information capability, while in another, they oppose strengthening consumers' information capability [9].

In order to achieve better profits, enterprises look for the right time and improve their sales further by changing consumers' information capability. At the same time, enterprises try their best to avoid the increase of consumer information capacity beyond a certain range, which will lead to the decline of the overall profits of enterprises. Therefore, it is necessary to study and analyze the market supply and demand relationship after enterprises change their information capability.

The standard supply and demand law in economics relates price and quantity; equilibrium is achieved when the consumers' downward demand curve and the firm's upward supply curve intersect. When Alfred Marshall more than a century ago first systematically studied the law and its applications, he used it merely as a convenient technical device [10]. Neoclassical economics since has made it the most important theoretical pillar. The core content of the supply-demand law has remained the same over the past century, in which the world economy has undergone dramatic transitions. However, products in the modern economy are much more complex after a century later, and hence the capability to ascertain their quality from the consumers' side plays a paramount importance in purchase decisions.

In the days of Mill and Ricardo, there were already vocal critiques by well-known thinkers like Charles Babbage [9] and Clie Leslie [11], questioning the assumption of classical economics of perfect information capability. Fast forward to 1970, Akerlof's work [12] on the 'Lemons Problem' clearly pointed out that strong information asymmetry about the product's quality can lead to 'market failures'. Mutually beneficial deals between sellers and buyers may not happen, if the buyers cannot reliably determine the quality of the objects under transaction. Despite much current research on many other interesting areas of Information Asymmetry [13-16], the fundamental insight of Akerlof is not yet adequately incorporated into mainstream economics. In standard textbooks one encounters 'price' and 'quantity', rarely 'quality' is adequately modeled. Yi-Cheng Zhang [8] designed a model for the supply-demand law with quality and limited information capability. In this paper we can easily find that the limited information capability can be changed in know.

In this work we shall consider an alternative version of the supply-demand law, with quality and imperfect information as the key ingredients. We consider a continuously varying degree of imperfect information, with the view in Supply and Demand Law under Limited Information as a special [9], extreme case. We posit that in all economic transactions, some degree of information imperfection always exists. In the modern economy, the conduct of daily life necessitates a myriad of products and services, which become ever more complex in their visible and invisible features. On the other hand, enterprise can change the quality and imperfect information economic way, and enhanced the demand in short time.

\section{Demand law under variable information}

Consumers have certain information capability in the market. They can perceive the service quality of products. When the information capability of consumers is infinite, they can fully perceive all the information of products. However, when the information capability of consumers is insufficient, or when it comes to information capability, they cannot feel the information of goods at all. On the one hand, consumers' information capability comes from their own consumption experience; on the other hand, it comes from the product information and service provided by producers for the society. Just as Apple's mobile phone quickly takes consumers' information capabilities on mobile phones to a new level, and it also creates more demand. Therefore, we can see that consumers' information capability depends on their own cognition and the quality of products provided by producers, both of which will affect the market demand for products.

In this paper, the quality of the products is not use money to measure (such as before the iPhone appeared, some mobile phone the price is higher than the apple mobile phone, but when it emerges, great changes have taken place in social cognitive quality of the products). Therefore, product quality $(Q)$ and product price $(P)$ are treated as independent variables in the research process of this paper. Before or during the appearance of high-quality products, some consumers will buy products with higher prices and lower quality. The correlation between quality and price can often be dealt with through market transactions, which often depends on the market information capability of consumers.

This article focuses on the whole market demand, the total demand in the market comes from $N$ consumers. Although the information capacity of these consumers tends to have some differences, there is always an average information 
capacity, we call that market average information capacity. The total market demand can be expressed as:

$$
q(Q, p, \varepsilon)=\sum_{i=1}^{N} q_{i}(Q, p, \varepsilon)
$$

Since potential buyers can decide to buy a product or give up buying a product, it can be considered that each product has strong substitutability. Suppose the total demand of the markets where all $N$ potential consumers purchase the product is 1 , and here we consider the total demand of the market as 1 , when the total market demand is 0.3 , it means that $30 \%$ of the consumers in the market are willing to purchase product. This article focuses on product quality, price and information capabilities are used unspecified units of the ratio. Therefore, the number of purchases $(q)$ is linearly proportional to the "likelihood" of the consumer purchasing the product.

It can be found that the quality of the products is given a new role. However, consumers often have weaker sensitivity to the quality of the products. That is, when the sellers in the market make the corresponding opaque information, the consumer's behavior reaction on quality-driven consumption will be slow. This relationship is described [13] as follows:

$$
q(Q, \varepsilon)=A\left(Q-A Q_{0}\right) /\left(1-A Q_{0}\right)
$$

where $A$ is the above-mentioned confidence factor. Note that $q(Q \max , \varepsilon)=A$, for any $\varepsilon$. In proposing the above formula, we try to keep the functions simple and whenever possible, linear functions are preferred. $Q_{0}=7 / 8$. The choice of parameters seems to be somewhat contrived; this is because the formula is a special example of the full expression $q$ $(Q, p, \varepsilon)$.

\section{Changing the limited information capabilities through economic way}

Obviously, when information capabilities cannot be changed by external forces, the market demand tends to move forward to the current information capabilities. As a result, many excellent products cannot be sold well in the market or have to wait for longer time to produce sales on the outbreak. If the timing of a good product entering the market is not good, it is very likely that the product will die. For example, when a product enters the market, the market does not know enough about the product, then the consumer does not purchase the product, causing the product disappeared. For most good products often need to wait for a long time to go through this process, this process is a waste of consumers and social resources. Therefore, when new and excellent products change, we can change the information capabilities of consumers through external means (such as increasing the popularity of products), so that the original demand tracking changes (or increase demand) and the enterprises can better provide services for the community.

Under the framework of the information economics and some current research, we can easily find out that the external sales can increase the overall sales volume. Lee W J and Kim D S [17] pointed out that the demand per unit time market is affected by the product price and product marketing costs. Obviously, the amount of marketing costs can change consumers' perceptions of product (or informative), so this article uses the model presented by Lee W J, Kim D S to describe the firm's investment in changing market information capabilities [17]. Using $M$ to represent the firm's investment needed to change consumer information capabilities, the increase in sales can be expressed as [18].

$$
\Delta q=K p^{-\alpha} M^{\beta}
$$

Therefore, $K$ is coefficient, $p$ is price, $\alpha$ is price effect, $\beta$ is $M$ effect. In the second part, as an invisible variable $p$ should be hidden in $Q$, so we can also remove $p$ and $\alpha$. Then the quality of goods is $Q$. the sales is $q$, unit profits is $g$, and total profits is $G$.

When the quality and price does not change, in order to increase sales, the external means used can be seen as enhancing the information capability of consumers. When this capability is changed, it tends to fall back quickly in unsustainable investments. This process often needs to be maintained for some time to maintain the market information capacity at this level so that the market can adapt to this level of information.

To change sales volume through external forces is essentially to change information capability. At this time, consumers in the market are more likely to obtain sales information, and then change the information ability of the market. In order to describe this phenomenon better, this article made the hypothesis as follows.

Hypothesis 1. This change in the information capacity can be seen as an instantaneous completion, but maintaining this information capacity requires constant external input, namely through the investment of the external force to shorten the time of the information the power to change demand.

Hypothesis 2. For any kind of product, there is a market optimal information capability, so that maximize corporate profits, we define as $\varepsilon^{*}$.

In response to market conditions, we make the following assumptions that manufacturers fully understand the quality of their products and that they have ended their production. Market intelligence capabilities are far below $\varepsilon^{*}$ when $M$ is not invested. This is because when the market information capacity is too abundant, it has already begun to affect the 


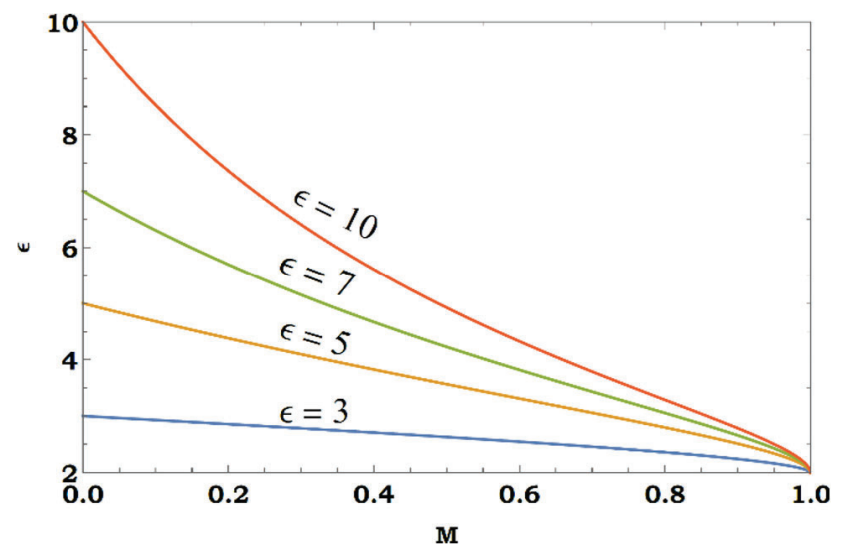

Fig. 1. The effect of $M$ on $\varepsilon$ for different $\varepsilon_{0}$.

overall revenue of the market. At this time, the external resources invested by enterprises tend to reduce the information capacity. In this section, we would not discuss it. We only discuss the market demand before and after the product has entered maturation period so that the role of external forces $\varepsilon$ in the market is far less than $\varepsilon^{*}$.

After increasing the external force, the market demand has two parts. The first part comes from the demand of the market under the original information abilities. The other part comes from the change of external forces. At this moment, the introduction of external force $\varepsilon$ can describe the change as shown in Eq. (4).

$$
q\left(\varepsilon_{1}, Q\right)=q\left(\varepsilon_{0}, Q\right)+K M^{\beta}
$$

In the supply and demand law under limited information of Zhang [9], in consideration of the quality of goods and price given, there is an information capacity to maximize the benefits of business, and then increase the consumer's information capacity will have a negative impact on the enterprise. Therefore, enterprises have the power to change the ability of consumers' information. Therefore, when the $\varepsilon$ is changed, the $\varepsilon$ can be made at most to the maximum benefit $\varepsilon^{*}$ that can be made by the enterprise. At this time, the sales volume in the market corresponds to $q^{*}\left(\varepsilon^{*}\right)$. Therefore, $K$ is considered as a function of $q(\varepsilon)$ and $q^{*}\left(\varepsilon^{*}\right)$ appropriately protect the enterprise increase investment.

$$
K=q^{*}\left(\varepsilon^{*}\right)-q(\varepsilon)
$$

When $Q$ is fixed, $q^{*}\left(\varepsilon^{*}\right)$ is fixed value and $q(\varepsilon)$ is uniquely determined by $\varepsilon$.

$$
q^{*}\left(\varepsilon^{*}\right)=\frac{8 \sqrt{1-Q} Q^{2}}{7(1+\sqrt{1-Q})(1+\sqrt{1-Q}-Q)}
$$

And defined at $Q=1, q^{*}=1$. $\varepsilon_{1}$ is the result after the addition of $\varepsilon$ changes, the $q(Q, \varepsilon)=A\left(Q-A Q_{0}\right) /\left(1-A Q_{0}\right)$, and $Q_{0}=7 / 8, A=1 /(1+\varepsilon)$. When $Q=0.5$ and $\beta=1$, optimal $\varepsilon=\frac{8 \sqrt{1-Q} Q^{2}}{7(1+\sqrt{1-Q})(1+\sqrt{1-Q}-Q)} \approx 1.98744$.

As can be seen from Eq. (4), the effect of $M$ on $\varepsilon$ for different $\varepsilon_{0}$ is shown in the Fig. 1 :

It can be found that given the quality of $\mathrm{Q}$ the earlier the firm can achieve better sales by changing the market information capability through external forces, the better result will be achieved. That is, in the situation that $Q$ has already been determined, the sooner the $M$ is put into effect, the more obvious the effect is. In the situation where the market conditions are same, the market responses of the products of different qualities after entering $M$ are obviously different. (See Fig. 2.)

The products with better quality are easier to be recognized by the market. In the case of investing the same $M$, the market has a much higher awareness of the products with good quality than the products with general quality, that is to say, the effectiveness of $M$ is obviously different for products with different quality. At the same time, it also shows that the better the quality of the product, the sooner it should be put into $M$.

\section{Supply side}

When the quality of products produced by enterprises has certain differences, the corresponding optimal market also has some differences. Therefore, when observing the specific market investment resources of a certain product, it is necessary to clarify the quality of its products $Q$, otherwise it may have the opposite effect. When it is clarified that the quality is a certain $Q, M$ becomes a new variable. However, $M$ as a one-time total expenditure should be averaged in the cost per unit of product represented by the sales volume when calculating unit profits. The definition as follows.

$$
M_{1}=M \cdot q\left(\varepsilon_{1}\right)=M \cdot q\left(\varepsilon_{0}, M\right)
$$




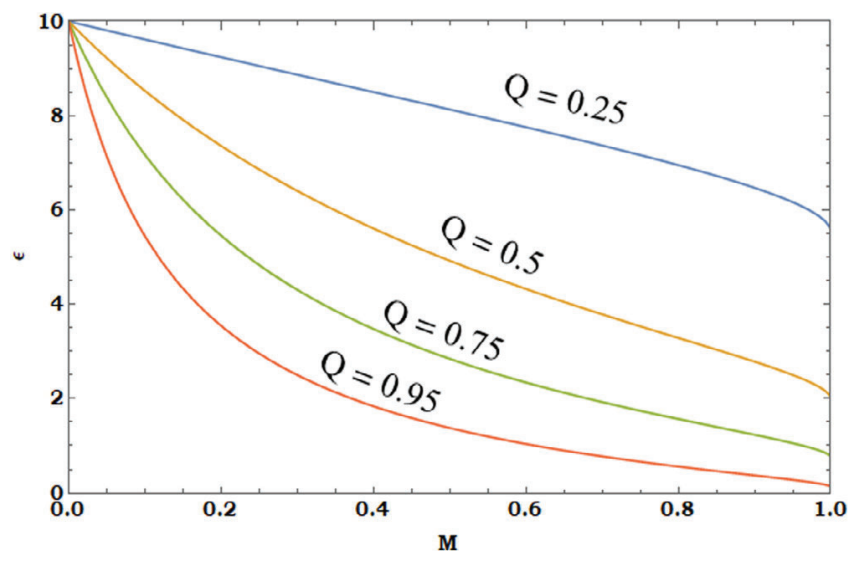

Fig. 2. The products of different qualities after entering $M$.

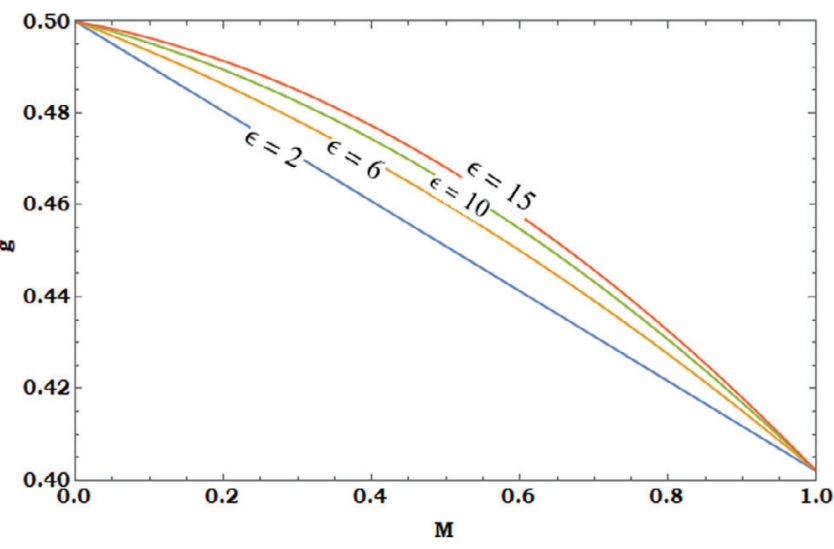

Fig. 3. Different $\varepsilon_{0}$ under $Q=0.5$.

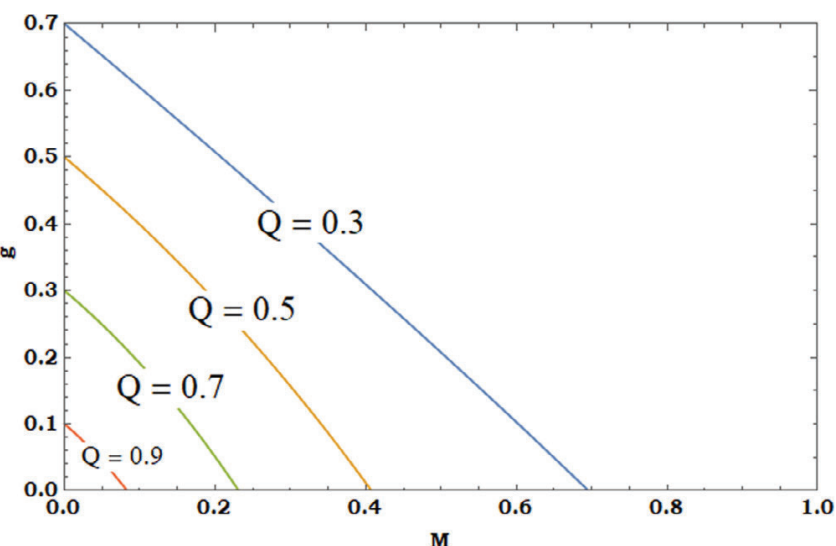

Fig. 4. Different $Q$ under $\varepsilon_{0}=5$.

$$
\begin{aligned}
g\left(Q, M, \varepsilon_{0}\right) & =1-Q-M_{1}\left(\varepsilon_{0}, M\right) \\
& =1-Q-M \cdot q\left(\varepsilon_{0}, M\right)
\end{aligned}
$$

Obviously, in the given case, $g\left(Q, M, \varepsilon_{0}\right)$ has a different display than the initial $Q$ and $\varepsilon_{0}$, and the Fig. 3 shows that for different $Q=0.5$, we will give different $\varepsilon_{0}$.

When $\varepsilon_{0}=5$, there are the following phenomena for different $Q$ as shown in Fig. 4 . 


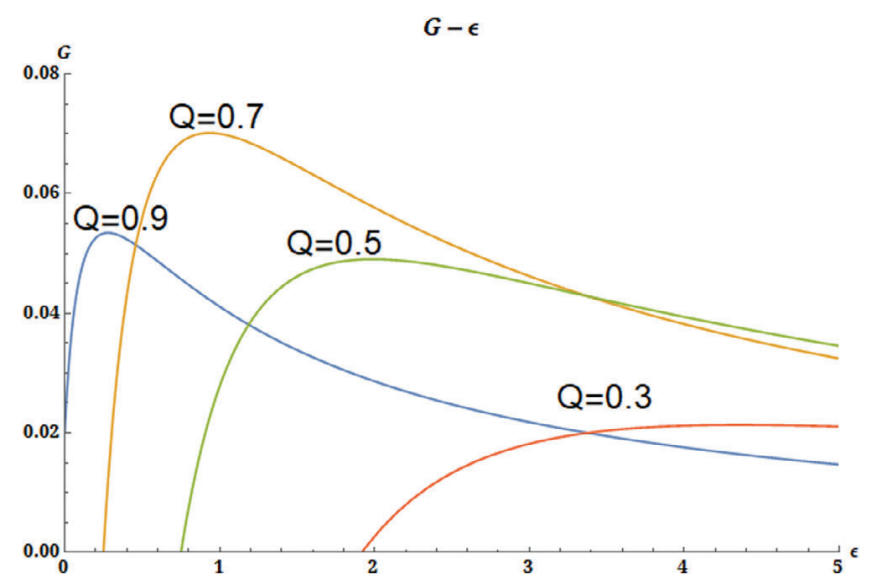

Fig. 5. The firm's total profit under different $Q$.

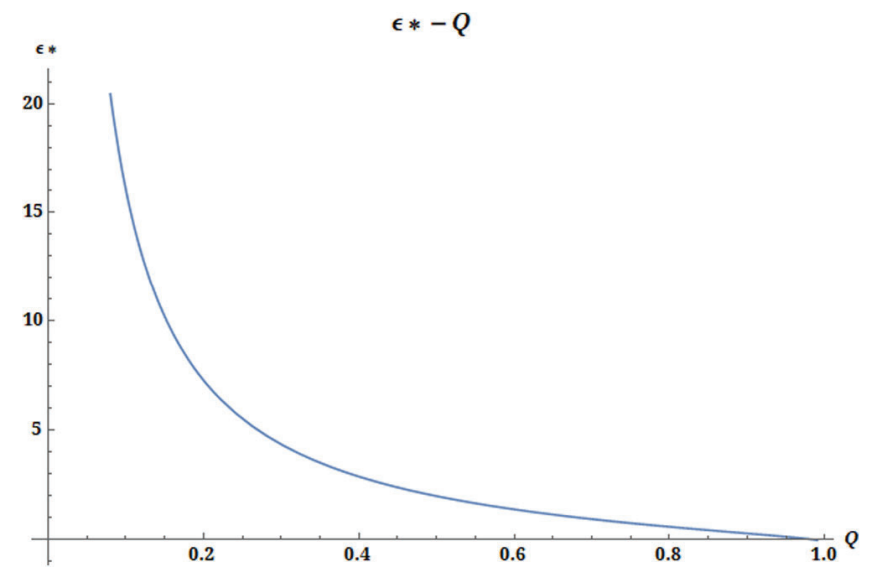

Fig. 6. The optimal $G$ is the corresponding market information capacity.

\section{Total profit}

\subsection{The total profit under normal circumstances}

We are ready to take the demand and supply sides to meet in the market. The firm's total profit from a given type of product is defined as

$$
\begin{aligned}
G(Q, \varepsilon) & =g(Q) q(\varepsilon, Q) \\
& =(1-Q) A\left(1-A Q_{0}\right) /\left(1-A Q_{0}\right)
\end{aligned}
$$

We can find products in different quality, with the increase of consumers' information capability, the profits of the enterprises is quite different. When the quality of products is poor, the benefits they can get will increase with the consumers' information capability reduce. When the quality of products produced by enterprises is within a certain range, the total profits of enterprises will increase with the increase of information capabilities. However, for the products with different qualities, there is always an information capability that enables them to obtain maximum profits. That is, when $Q$ is determined, the optimal $G$ is the corresponding market information capacity (see Figs. 5 and 6 ):

$$
\varepsilon=\varepsilon^{*}=\frac{-7+15 Q-8 Q^{2}-7 \sqrt{1-3 Q+3 Q^{2}-Q^{3}}}{8\left(-Q+Q^{2}\right)}
$$

Obviously, the maximum consumer information capacity required by the optimal earnings of enterprises increases with the increase of $Q$ (the information capacity decreases with the increase of $\varepsilon$ ). In this case, if the enterprise gives the quality $Q$ and guides the consumer to the corresponding optimal information capability, the quantity of products that the 


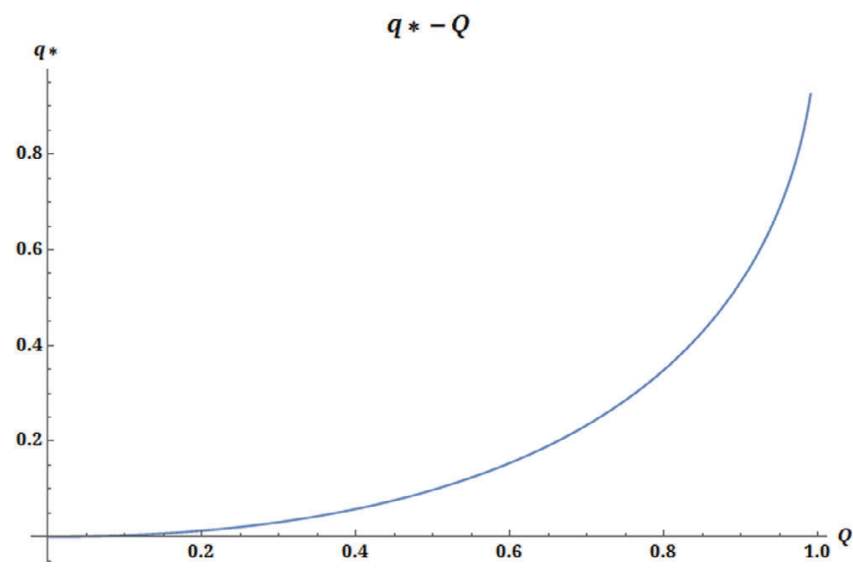

Fig. 7. The change of market demand with quality $Q$.

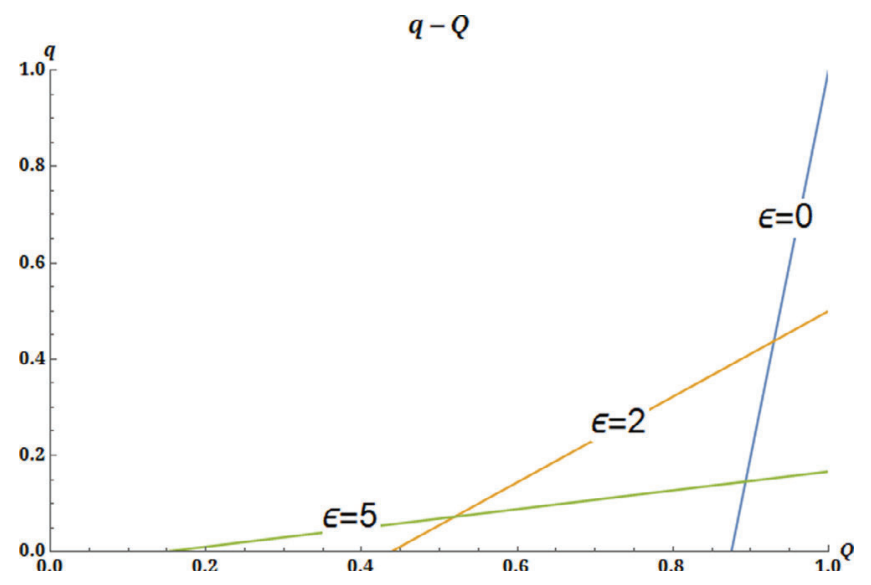

Fig. 8. The different information capabilities to enhance the contribution of sales of enterprises.

enterprise can sell can be converted into an equation:

$$
q^{*}\left(\varepsilon^{*}, Q\right)=\frac{\frac{1}{1+\varepsilon^{*}}\left(Q-\frac{1}{1+\varepsilon^{*}} Q_{0}\right)}{1-\frac{1}{1+\varepsilon^{*}} Q_{0}}
$$

Fig. 7 shows the change in market demand with quality $Q$ when the market information capacity is exactly the maximum total profit under the condition of producing different quality products. That is, the demand of high quality products increases obviously under appropriate market conditions. In Fig. 8, we can find that the higher the quality of the product, the greater the contribution of information capabilities to the sales of the enterprises.

At the same time in given a quality product and the corresponding quality of the best information capabilities, the enterprise will get the highest sales profit, can be expressed as $G^{*}\left(\varepsilon^{*}, Q\right)=g(Q) q^{*}\left(\varepsilon^{*}, Q\right)$

Fig. 9 reflects the change in the maximum of total profit with $Q$ in the case of different markets with the most appropriate market information capability. And when $q=7 / 8$, the most suitable market information capacity at this time is also $3 / 4$, which can reach the highest total profit of $1 / 14$, and the conclusion is consistent with previous studies [9].

\subsection{Total profit after joining $M$}

Enterprises relieve resources to the market through the relevant way, like making the market demand increase to a certain extent and leaving the company's overall profit rules change. In general, when the $Q$ is determined, the manufacturer makes use the input of $M$ to make changes so as to raise the instantaneous total profit. Of course, this is a continuous process, but due to the addition of $M$, the cost and the total amount available to the enterprise profit has changed. 


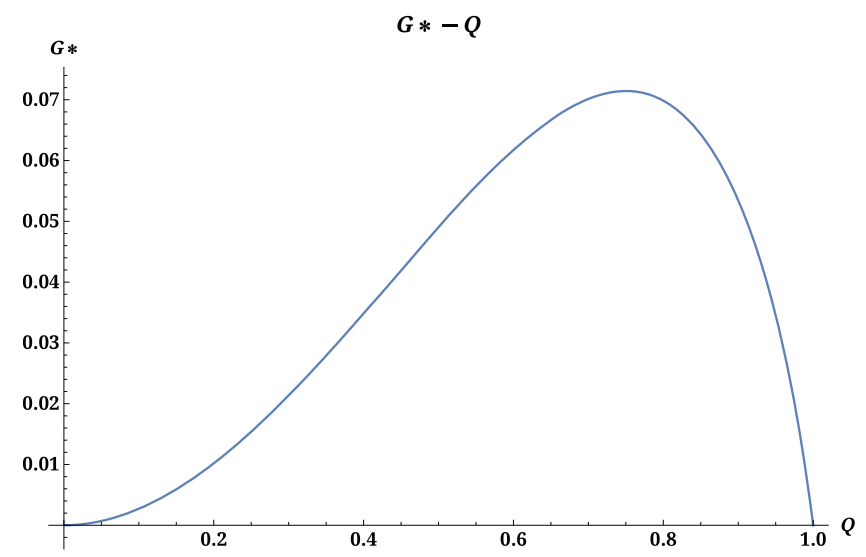

Fig. 9. The change in the maximum of total profit with $Q$.

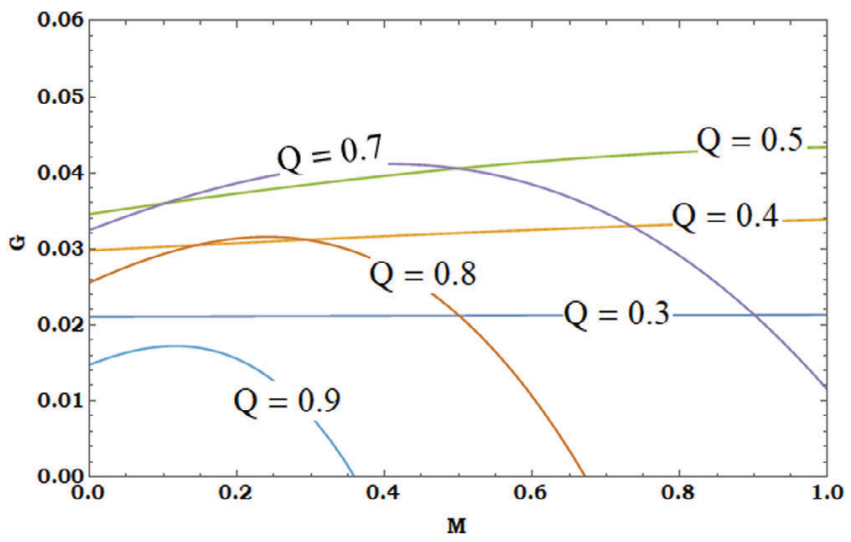

Fig. 10. Total profit after the investment of different quality products $M$.

From the above we can see that $M_{1}$ represents the unit cost of social investment in the growth in demand, after being classified as $0-1$ between the demand: $M_{1}=M q\left(\varepsilon_{1}\right)$.

$$
G n\left(\varepsilon_{1}, M_{1}\right)=\left(1-Q-M_{1}\right) * \frac{\frac{1}{1+\varepsilon_{1}}\left(Q_{0}-\frac{Q_{0}}{1+\varepsilon_{1}}\right)}{1-\frac{Q_{0}}{1+\varepsilon_{1}}}
$$

Here, the parameter $\epsilon$ in Gn refers to the profit that can be obtained when the original market information capability is converted from $\dot{\epsilon}_{0}$ to $\dot{\epsilon}_{1}$ after the input of $M$. In the market, the information capability is $\dot{\epsilon} 0=5$, the instantaneous total profit after the investment of different quality products $M$ is as Fig. 10:

It can be found that when the quality of the product is higher than the quality of the product into the same resources, the profit increase is greater than the quality of the smaller product. At the same time, for a product with different qualities and initial information capabilities, there is an optimal $M$ that maximizes the profitability of the enterprise. At this point, it should be noted that the market information capability cannot be upgraded to an area greater than the optimal information capacity, and if it is promoted to this area, additional resources $M$ are needed to reduce the market's information capability or confuse the audiovisual products.

\section{Summary}

This paper studies the relationship between supply and demand in the case of variable market information capability. The results show that the earlier an enterprise can let the market know the product when quality $Q$ is determined, the higher the profits it will generate,but the premature input cost of the enterprise may not achieve the optimal income. So the most appropriate time is a function of quality and external resources. At the same time, when the products provided by the market are different, the products with better quality are more likely to be recognized by the market. For the same information capability, there is a significant difference in the external resources required for different quality products. Overall, this paper is a further supplement to the market demand and supply relationship under the limited 
information capabilities, which is more in line with the basic social phenomenon. However, this paper assumes that the social information capabilities will show an instantaneous rise and the instantaneous fallback linearity is different from the actual production. Under the spread of the network economy, it is possible to quickly transform the information capabilities of consumers. The proposed theoretical model helps to change the information capabilities through other means. In the future, we can study ways and means of changing information capabilities, which can serve as future research directions. At the same time, the theoretical model provides a basis for enterprises to choose the timing of external resource input according to the quality of the products they provide. Under this basis, companies will get more benefits at a lower cost. The research of this paper effectively provides a set of basic research frameworks for studying the changes in market information capabilities caused by external inputs and then transforming them into market demand.

\section{Acknowledgment}

Funding: National Natural Science Foundation of China (71271126), (61374177).

\section{References}

[1] C. Geertz, H. Geertz, L. Rosen, et al., Meaning and order in moroccan society three essays in cultural analysis, Man 15 (3) (1979) 554

[2] M. Medo, Y.C. Zhang, Market model with heterogeneous buyers, Physica A 387 (12) (2008) 2889-2908.

[3] Q. Li, T. Yang, E. Zhao, et al., The impacts of information-sharing mechanisms on spatial market formation based on agent-based modeling, PloS One 8 (3) (2013) e58270.

[4] C. Geertz, The Social History of an Indonesian Town, Greenwood Press, 1975.

[5] G. Akerlof, The market for "lemons": Quality uncertainty and the market mechanism, in: Essential Readings in Economics, Macmillan Education UK, 1995, pp. 488-500

[6] H. Liao, R. Xiao, D. Chen, et al., Firm competition in a probabilistic framework of consumer choice, Physica A 400 (2) (2014) 47-56.

[7] J. Johnson, A. Nowak, P. Ormerod, et al., Non-Equilibrium Social Science and Policy, Springer International Publishing, 2017.

[8] Y.C. Zhang, Informational selection \& natural selection, Physics Procedia 3 (5) (2010) 1941-1955.

[9] Y.C. Zhang, Supply and demand law under limited information, Physica A 350 (2) (2005) 500-532.

[10] A. Marshall, Principles of economics: An introductory volume, Soc. Sci. Electron. Publ. 67 (1742) (1920) 457.

[11] E.A.M. Charlesbabbage, On the economy of machinery and manufactures, Phil. Mag. 1 (3) (2010) $208-213$.

[12] N. Calin, The unknown/known economic and financial crisis, Revista Econ. supplement (1) (2012) 549-553.

[13] G. Akerlof, The market for lemons: Quality uncertainty and the market mechanism, in: Essential Readings in Economics, Macmillan Education UK, 1995, pp. 488-500.

[14] A.M. Spence, Market signaling, information transfer in hiring and related processes, in: Market Signaling: Informational Transfer in Hiring and Related Screening Processes, Harvard University Press, 1974

[15] Z.K. Zhang, C. Liu, X.X. Zhan, et al., Dynamics of information diffusion and its applications on complex networks, Phys. Rep. 651 (2016) 1-34.

[16] X.X. Zhan, C. Liu, G. Zhou, et al., Coupling dynamics of epidemic spreading and information diffusion on complex networks, Appl. Math. Comput. 332 (2018) 437-448.

[17] W.J. Lee, D.S. Kim, Optimal and heuristic decision strategies for integrated production and marketing planning, Decis. Sci. 24 (6) (2010) $1203-1214$.

[18] Dezsö Szalay, Monopoly, non-linear pricing, and imperfect information: a reconsideration of the insurance market, Working Paper, in: Warwick Economic Research Papers, No. 863, University of Warwick, Department of Economics, Coventry, 2008. 